\title{
The Role of Substance Use and Emotion Dysregulation in Predicting Risk for Incapacitated Sexual Revictimization in Women: Results of a Prospective Investigation
}

\author{
Terri L. Messman-Moore, Rose Marie Ward, and Noga Zerubavel \\ Miami University
}

\begin{abstract}
Incapacitated sexual assault (ISA) is the most common form of sexual victimization experienced by college women. Although ISA victims are at risk for future assaults, few studies have examined mechanisms responsible for ISA revictimization besides heavy drinking. Using a prospective design, the present study examined whether emotion dysregulation, given its association with interpersonal trauma and substance use, increases risk for revictimization among women with a history of ISA above and beyond the effects of substance use. Female college students $(n=229)$ completed a baseline assessment followed by assessment of incapacitated sexual assault over a 9-week follow-up period. Approximately $36 \%$ of participants reported a history of ISA, and $73 \%$ of those victimized during the study had a history of ISA. Revictimized women reported higher levels of alcohol-related problems, greater marijuana use, greater emotion dysregulation, and higher levels of fear and guilt prior to experiencing ISA during the study; however, they did not consume more alcohol than previously victimized women. In a logistic regression analysis, guilt, emotion dysregulation, and marijuana use accurately classified $78.9 \%$ of ISA revictimized women. Women with a history of ISA are at substantial risk for ISA revictimization. Findings suggest that even very small increases in emotion dysregulation, particularly in impulsivity, as well as marijuana use, impact revictimization risk substantially. Efficacy of interventions to reduce ISA revictimization may be improved if emotion dysregulation is addressed.
\end{abstract}

Keywords: incapacitated sexual assault, revictimization, emotion regulation, alcohol consumption, college students

Recent research indicates that alcohol-involved or incapacitated sexual assault (ISA) is widespread. Compared to forcible assault, sexual assault following alcohol or drug consumption is far more common among female college students (Lawyer, Resnick, Bakanic, Burkett, \& Kilpatrick, 2010), an experience reported by almost three-quarters of rape victims surveyed in a large, multisite national study (Mohler-Kuo, Dowdall, Koss, \& Wechsler, 2004). After entering college, women's risk for ISA increases whereas risk for forcible sexual assault decreases (Krebs, Lindquist, Warner, Fisher, \& Martin, 2009). Not surprisingly, women's alcohol

This article was published Online First December 31, 2012.

Terri L. Messman-Moore and Noga Zerubavel, Department of Psychology, Miami University; Rose Marie Ward, Department of Kinesiology \& Health, Miami University.

This research was funded by a grant to Terri L. Messman-Moore from the Alcoholic Beverage Medical Research Foundation (ABMRF). ABMRF had no role in the study design, collection, analysis or interpretation of the data, writing the manuscript, or the decision to submit the article for publication. We acknowledge the support of numerous research assistants, whose hard work and dedication made this work possible. Finally, we to express our gratitude to the women who participated and appreciation for their commitment to this prospective study and their willingness to share information about potentially distressing unwanted sexual experiences.

Correspondence concerning this article should be addressed to Terri L. Messman-Moore, Department of Psychology, Miami University, 90 North Patterson Avenue, Oxford, OH 45056. E-mail: MessmaT@miamioh.edu use appears to be associated only with ISA and not forcible assault (Testa, Livingston, VanZile-Tamsen, \& Frome, 2003). Women's marijuana and other drug use are also associated with ISA, although to a lesser extent than alcohol use (Lawyer et al., 2010). In the only prospective study to examine ISA, monthly binge drinkers were more likely to report incapacitated versus forcible victimization (McCauley, Calhoun, \& Gidycz, 2010). Such findings suggest that reducing women's alcohol consumption should decrease risk for ISA (Testa \& Livingston, 2009). However, the only relevant study that focused on intervention indicates that reducing women's drinking does not directly diminish revictimization risk among women with previous histories of ISA (Clinton-Sherrod, MorganLopez, Brown, McMillen, \& Cowell, 2011). Thus, although women's alcohol use is associated with increased risk of ISA, surprisingly reduction in use is not associated with decreased rates of later revictimization. Although ISA victims are at risk for future assaults, few studies have examined mechanisms responsible for ISA revictimization beyond heavy drinking. More research is needed to understand factors that impact vulnerability for ISA revictimization. Using a prospective design, the present study examined whether emotion dysregulation, given its association with interpersonal trauma and substance use, increases risk for revictimization among women with a history of ISA, above and beyond the impact of alcohol and drug use.

Some women use alcohol to cope with psychological distress arising from sexual assault, such as fear, hostility, or guilt (Miranda, Meyerson, Long, Marx, \& Simpson, 2002). For individuals 
who lack effective emotion regulation skills, negative affect may be experienced as overwhelming, leading to maladaptive behaviors (e.g., substance use) to regulate distress. Although emotion dysregulation is related to negative affect, it is a distinct construct that impacts both emotional experience and behavioral responses (Bradley et al., 2011). Indeed, emotion dysregulation is thought to underlie risky behavior linked to revictimization, including risky sexual behavior and substance use (Filipas \& Ullman, 2006). Nonetheless, few studies have explicitly examined emotion dysregulation and revictimization. Among female prison inmates, revictimized women report greater emotion dysregulation, including greater emotional nonacceptance, lack of emotional clarity and awareness, and a greater tendency to engage in impulsive behavior when distressed (Walsh, DiLillo, \& Scalora, 2011). Emotion dysregulation is also linked with risky sexual behavior in college women, which predicts revictimization (Messman-Moore, Walsh, \& DiLillo, 2010).

Particular components of emotion dysregulation may impact revictimization vulnerability more than others. Lack of emotional awareness or clarity may impair risk perception (e.g., interpretation of fear cues), and thus increase risk for ISA revictimization. Engaging in impulsive behavior in response to negative affect is associated with problematic alcohol use and negative alcohol-related consequences (Magid \& Colder, 2007), although it has not yet been examined as a risk factor for revictimization. Elevations in impulsivity may increase the likelihood of entering potentially risky situations, or using alcohol or drugs with unfamiliar companions, which may increase revictimization risk. Because earlier studies examining emotion dysregulation and sexual revictimization used retrospective, cross-sectional designs, it is still unknown whether emotion dysregulation problems actually precede revictimization and whether difficulties in emotion regulation are initially greater among individuals who later become revictimized.

\section{Purpose}

Identifying factors that distinguish women who are revictimized from those who are not is essential to the development of effective interventions to prevent revictimization. Moreover, earlier studies failed to examine ISA separately, potentially obscuring the significant impact of victim substance use on risk for ISA (Testa, 2004). Thus, a primary aim of the study is to clarify the role of alcohol use in ISA-related revictimization. It was hypothesized that women's heavy alcohol consumption and alcohol-related problems, as well as drug use, would predict incapacitated sexual revictimization. Another important aim of the study was to test a hypothesis that emotion dysregulation predicts incapacitated sexual revictimization after considering the impact of alcohol use, drug use, and negative affect. Given the predictive nature of the research questions, it was critical to use a prospective design to determine whether substance use and emotion dysregulation preceded ISA. Because of the high prevalence of ISA in college populations (Lawyer et al., 2010), and college women's increased risk for ISA (Krebs et al., 2009), the current study focused on risk factors for ISA revictimization among college women.
Method

\section{Participants}

Participants were 229 female undergraduate students enrolled at a midsized university in the Midwest. Participants' average age was 19.74 ( $S D=1.36$, range $18-23)$. Slightly less than one third $(29.3 \%)$ were in the first year of college, $14.1 \%$ were sophomores, $27.2 \%$ were juniors, and $29.3 \%$ were seniors. The majority of participants were Caucasian $(92.4 \%)$ and middle- to upper-class (55.6\% reported past year family income of $\$ 100 \mathrm{~K}$ or more). The majority were sexually active (84.7\%) and unmarried $(95.7 \%)$; $48.2 \%$ reported being in an exclusive dating relationship.

\section{Measures}

ISA. The revised Sexual Experiences Survey (SES; Koss et al., 2007) was administered at Time 1 (the first week of the study) to ascertain ISA (and forcible) victimization experiences from age 14 until entrance into the study. The revised SES was readministered weekly (Times 2-10) to identify prospective ISA victims. For each week, eight different questions assessed unwanted sexual experiences related to respondent alcohol and drug consumption for each of three different types of unwanted sexual contact (kissing/fondling, oral-genital contact, and intercourse). This resulted in 24 variables comprising ISA at each time point. Affirmative responses across the 9-week period were aggregated such that prospective ISA was coded as a dichotomous variable (yes $=1$, no $=0)$.

Child sexual abuse. The Childhood Trauma Questionnaire (CTQ; Bernstein \& Fink, 1998) is a 28-item inventory that was administered at Time 1 to determine whether participants had experienced child sexual abuse (CSA) prior to age 14. Participants' scores were classified into categories of abuse severity based on published recommendations; only those individuals reporting moderate to extreme CSA were considered abused. The CTQ has demonstrated reliability and validity (Bernstein \& Fink, 1998); internal consistency coefficient for the CSA subscale was .85.

Alcohol use, alcohol-related problems, and drug use. Alcohol consumption was assessed at Time 1 using measures consistent with national studies of college student alcohol use (e.g., CAS; Wechsler \& Nelson, 2008). Participants were asked if they had ever consumed alcohol, how old they were the first time they consumed alcohol, their highest number of drinks consumed in a single drinking occasion in the last 30 days, and number of times in the last month that they had consumed four or more drinks in a row on one occasion. In addition, the Alcohol Use Disorders Identification Test (AUDIT; Babor, Higgins-Biddle, Saunders, \& Moteiro, 2001) was used to assess alcohol consumption (Questions 1-3; AUDIT-C), as well as symptoms of dependence and alcoholrelated problems (Questions 4-10) in the past year. The AUDIT-C shows high levels of sensitivity and specificity in screening for alcohol dependence, any alcohol use disorder (AUD), and risky drinking. Among college students, a cutoff of $\geq 5$ points on the AUDIT-C yields the highest values of sensitivity and specificity for alcohol dependence or risky drinking (Dawson, Grant, Stinson, $\&$ Zhou, 2005). In the current sample, internal consistency reliability was .80 for the AUDIT-C and .75 for the dependence/ problems subscale. Drug use was assessed with seven questions 
from the Frequency of Involvement subscale of the Cognitive Appraisal of Risky Events Questionnaire-Revised (CARE-R; Fromme, Katz, \& Rivet, 1997; Katz, Fromme, \& D’Amico, 2000) measuring frequency of drug use in the previous 6 months.

Negative affect. Negative affect—fear, sadness, hostility, and guilt-was assessed at Time 1 with subscales of the Positive and Negative Affect Schedule (PANAS-X; Bagozzi, 1993). Each subscale score was computed by summing 6 items, which used a 5-point Likert scale from 1 (very slightly or not at all) to 5 (extremely). Internal consistency Cronbach's alpha for the negative affect scales ranged from .79 (hostility) to .89 (sadness) in the current sample. Participants reported on past week emotion, although there is evidence that PANAS scales assess trait affect, which is stable and predictive across extended periods (Watson \& Walker, 1996).

Emotion dysregulation. The Difficulties in Emotion Regulation Scale (DERS; Gratz \& Roemer, 2004) assessed emotion dysregulation at Time 1 . The DERS is comprised of 36 items that are summed for a DERS total score or summed into six subscales scores. Higher scores indicate greater emotional dysregulation. All items are scored on a Likert scale from 1 (almost never) to 5 (almost always) and indicate how often the participant experienced the statement. Six subscale scores suggest a lack of emotional awareness characterized by the inability to attend to emotions (Awareness); lack of emotional clarity and personal understanding of emotions (Clarity); failure to accept feeling distressed (Nonacceptance); problems controlling behavior when experiencing negative affect (Impulse); limited access to effective emotion regulation strategies when distressed (Strategies); and difficulties accomplishing tasks when distressed (Goals). Internal consistencies (Cronbach's alpha) for the six scales ranged from .78 (Clarity) to .91 (Goals) in the current sample. Among untreated individuals, DERS scores are relatively stable over 14 weeks (Gratz \& Tull, 2010).

\section{Procedure}

The committee for human subjects in research approved all procedures. Participants were recruited through fliers posted on campus and advertisements in the student newspaper. The study spanned 10 weeks, with data collection at 1 -week intervals. The sample was comprised of four cohorts, each starting the study 1 week apart, in order to stagger the data collection. At the beginning of the study (Time 1), participants completed paper-and-pencil surveys. Women then completed online (Internet-based) surveys weekly (Times 2-9) and returned to complete paper-and-pencil surveys at Time 10. Participant responses were linked via a unique identification number. All in-person data collection took place in group sessions staffed by female research assistants. Participants received an honorarium of $\$ 25$ for the first session, and were eligible to earn up to $\$ 75$ for Sessions 2-10 (prorated based upon number of surveys completed, up to $\$ 50$, with an additional $\$ 25$ for completion of all 10 surveys). Following participation each week, women received information regarding counseling and support services, as well as researcher contact information.

\section{Data Analysis}

All analyses were conducted with SPSS 18. Chi-square, analysis of variance (ANOVA), and multivariate analysis of variance
(MANOVA) were conducted to identify relevant ISA revictimization risk factors. These initial analyses included the entire sample to examine whether differences existed among revictimized women, previously victimized but not revictimized women, and nonvictims on study variables. To predict revictimization, logistic regression analyses were conducted with the subset of women with a prior history of ISA. All variables for which revictimized women differed from previously victimized women in the previous analyses were included as predictors in the two logistic regression analyses (i.e., with emotion dysregulation broadly defined and subtypes of emotion dysregulation).

\section{Results}

\section{Study Retention and Handling of Missing Data}

Participants in the study were drawn from a larger sample of 424 female undergraduate students. Participants completed an average of $9.12(S D=1.61)$ weekly sessions; $85.8 \%(n=364)$ of participants completed all 10 weekly sessions or only missed one session. Missing data on ISA victimization was minimal; $93.9 \%$ of the sample was missing less than 5\% (96.7\% missing less than $10 \%)$. Women with missing data who reported ISA were classified as ISA victims; women with missing data who did not indicate ISA were unable to be unequivocally classified as nonvictims ${ }^{1}$ and were excluded from analyses. There were no significant differences between the subset of women who provided complete victimization data $(n=255)$ and those who did not $(n=169)$ on study variables $(p s>.05)$. Missing data on other variables was random and minimal (less than 5\% missing on any remaining variables). To maximize sample size, analyses were conducted casewise. Distributions of predictor variables were normal and without significant outliers.

\section{Prevalence of ISA and Revictimization}

Incapacitated sexual revictimization occurred if a woman with a prior history of ISA (regardless of history of CSA or forcible sexual assault) experienced another episode of ISA during the 9-week follow-up period. Of the 255 individuals with complete victimization data (see Figure 1), 7.5\% $(n=19)$ reported CSA or forcible sexual assault after age 14 but did not report incapacitated assault. Given the focus on risk for ISA revictimization, these women were excluded. Among the remaining 236 participants, 92 women reported a history of ISA: $8.1 \%(n=19)$ reported prospective revictimization (ISA prior to as well as during the 10week study) and $30.9 \%(n=73)$ reported prior ISA without prospective victimization. In addition, $2.9 \%(n=7)$ reported ISA during the 10-week study (i.e., prospective victimization) but had no prior ISA victimization. Given the focus on factors that predict ISA revictimization, these women were excluded from subsequent analyses, resulting in a final sample of 229 women.

\footnotetext{
${ }^{1}$ It is impossible to determine whether participants who leave items blank on the SES have experienced unwanted sexual activity. Because recalling experiences of sexual assault can be distressing, some women may have been motivated to skip particular questions or participation in a week following an unwanted sexual experience. To be conservative, these individuals were excluded because they could not be labeled as nonvictims
} 


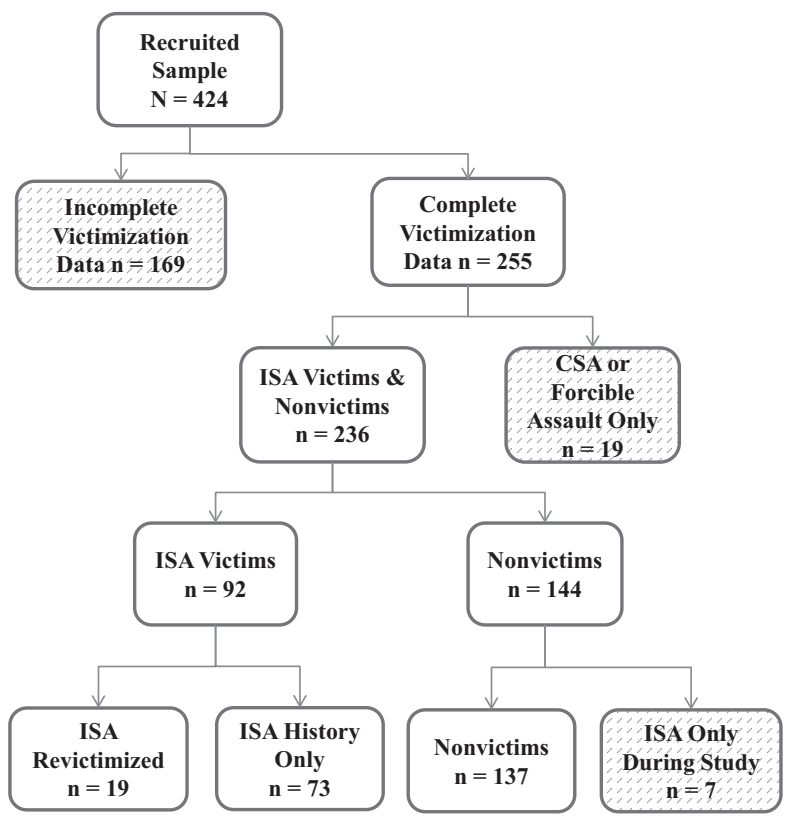

Figure 1. Participant flowchart. Shaded blocks indicate participants excluded from analyses. ISA = incapacitated sexual assault; CSA = child sexual abuse.

Among those who experienced ISA revictimization, 78.9\% $(n=$ $15)$ of cases involved only alcohol, $10.5 \%(n=2)$ involved alcohol and other substances, and $10.5 \%(n=2)$ involved other substances but not alcohol. Prior ISA was significantly associated with prospective ISA, $\chi^{2}(1)=17.19, p<.001, \Phi=.26 ; 20.7 \%$ of women with a history of ISA reported prospective ISA and $73.1 \%$ of women who reported ISA during the study (i.e., were prospectively victimized) had a history of ISA. There was no association between CSA and prior ISA, $\chi^{2}(1)=0.64, p=.43$, nor between CSA and ISA during the study, $\chi^{2}(1)=0.62, p=.43$. There were no differences in rates of ISA or revictimization among the cohorts $(p s>.48)$.

\section{Alcohol and Other Substance Use}

The average peak drinking occasion in the previous month was $6.13(S D=4.14$, range $0-20)$, and participants reported consuming four or more drinks on one occasion (heavy episodic drinking) almost twice in the previous month $(M=1.84, S D=1.41)$. The average AUDIT-C score was $5.01(S D=5.28)$, just exceeding the cut score of 5 which identifies college students with any AUD, alcohol dependence, and risky drinking practices as defined by the National Institute on Alcohol Abuse and Alcoholism (NIAAA) (Dawson et al., 2005). In the previous 6 months, 9.8\% of the sample reported using marijuana at least once. Drug use other than marijuana was very infrequent; participants who reported using drugs other than marijuana also reported using marijuana, therefore analyses including drug use focused on marijuana use only.

\section{Differences Between Revictimized and Nonrevictimized Individuals}

Demographics. Revictimized individuals did not differ from previously victimized or nonvictimized individuals in terms of age, race, or cohort.

Substance use and related problems. A MANOVA was conducted to determine whether, prior to experiencing ISA revictimization during the study, participants differed in terms of alcohol consumption and alcohol-related problems. The multivariate test was significant, Wilks' $\Lambda=.75, F(8,402)=7.88, p<.001$. All follow-up ANOVA tests were significant $(p<.001$; see Table $1)$. Women with a history of ISA (with or without revictimization) reported higher levels of alcohol consumption and alcohol-related problems than nonvictimized women. Revictimized women did not report greater consumption than previously victimized women but did report significantly higher levels of alcohol-related problems. A chi-square analysis also indicated that revictimized women were more likely to exceed the AUDIT-C cut-score for probable alcohol dependence (Dawson et al., 2005), and nonvictims were less likely than expected to exceed this cut-off. Revictimized women were 3.68 times more likely to report marijuana

Table 1

Differences Between Revictimized and Nonrevictimized Groups on Alcohol Use Variables

\begin{tabular}{|c|c|c|c|c|c|c|}
\hline $\begin{array}{l}\text { Baseline alcohol use } \\
\text { and problems }\end{array}$ & $\begin{array}{l}\text { Revictimized } \\
\quad(n=18)\end{array}$ & $\begin{array}{l}\text { Previously victimized } \\
\qquad(n=69)\end{array}$ & $\begin{array}{l}\text { Nonvictimized } \\
\quad(n=135)\end{array}$ & $F / \chi^{2}$ & $\eta^{2}$ & Cohen's $d$ \\
\hline $\begin{array}{l}\text { Highest no. of drinks } \\
\text { past month }\end{array}$ & $9.42^{\mathrm{a}}(3.89)$ & $7.39^{\mathrm{a}}(3.85)$ & $4.84^{\mathrm{b}}(3.84)$ & $17.40^{* * * *}$ & .15 & \\
\hline $\begin{array}{l}\text { No. of times drank } 4+ \\
\text { drinks past month } \\
\text { AUDIT-C }\end{array}$ & $\begin{array}{l}2.79^{\mathrm{a}}(1.13) \\
7.21^{\mathrm{a}}(1.78)\end{array}$ & $\begin{array}{l}2.38^{\mathrm{a}}(1.22) \\
6.06^{\mathrm{a}}(2.37)\end{array}$ & $\begin{array}{l}1.36^{\mathrm{b}}(1.36) \\
4.03^{\mathrm{b}}(2.68)\end{array}$ & $\begin{array}{l}19.32^{\text {***** }} \\
22.53^{\text {***** }}\end{array}$ & $\begin{array}{l}.16 \\
.18\end{array}$ & \\
\hline $\begin{array}{l}\text { AUDIT dependence/ } \\
\text { problems subscale } \\
\text { Percentage exceeding } \\
\text { AUDIT-C cut-off }\end{array}$ & $\begin{array}{c}6.68^{\mathrm{a}}(5.21) \\
89.5 \%^{*}\end{array}$ & $\begin{array}{c}4.70^{\mathrm{b}}(3.60) \\
58.9 \%\end{array}$ & $\begin{array}{l}2.09^{\mathrm{c}}(2.26) \\
30.8 \%^{*}\end{array}$ & $\begin{array}{l}27.14^{* * * *} \\
30.48^{* * * * *}\end{array}$ & $\begin{array}{l}.21 \\
.36\end{array}$ & .87 \\
\hline $\begin{array}{l}\text { Percentage reporting } \\
\text { Marijuana use }\end{array}$ & $36.8 \% *$ & $8.2 \%$ & $6.8 \%$ & $17.34^{* * * *}$ & .27 & \\
\hline
\end{tabular}

Note. Groups with different superscripts differ significantly at $p<.05$. Cohen's $d$ was computed only for differences between the revictimized and previously victimized groups; effect sizes for differences between revictimized and nonvictims are not reported. Scores $\geq 5$ on the Alcohol Use Disorders Identification Test (AUDIT) Alcohol Consumption subscale (AUDIT-C) are indicative of alcohol dependence in a college sample (Dawson et al., 2005). For chi-square analysis, groups differ from expected values, based upon standardized residuals $>1.96$.

${ }^{*} p<.05{ }^{* *} p<.01{ }^{* * * *} p<.001$. 
use than expected; the other groups' actual use did not differ from expected values.

Emotion dysregulation and negative affect. Two analyses (ANOVA and MANOVA) were conducted to determine whether participants differed in terms of emotion dysregulation and negative affect prior to experiencing ISA revictimization. An ANOVA indicated differences on the DERS total score between the revictimized group and the previously victimized and nonvictimized group, $F(2,217)=7.46, p=.001$ (see Table 2). The MANOVA examined differences among groups for the DERS subscales and negative affect. The multivariate test was significant, Wilks' $\Lambda=$ $.84, F(20,406)=1.87, p<.05$. Follow-up univariate ANOVA tests were significant for impulse, clarity, goals, fear, and guilt (see Table 2). Post hoc comparisons indicated revictimized women reported greater difficulties inhibiting impulsive behavior, greater fear, and greater guilt compared to previously victimized and nonvictimized women. There were no significant group differences for emotional clarity or goals, or between the previously victimized groups for strategies or hostility. Effect sizes for differences between revictimized and previously victimized women were in the medium range (Cohen's $d \mathrm{~s} \geq .5$ ) for negative affect and in the large range (Cohen's $d \mathrm{~s} \geq .8$ ) for DERS total score and difficulties in impulse control.

\section{Logistic Regression Analyses Predicting Prospective Revictimization}

To identify risk factors that distinguish women at risk for ISA revictimization, all women with a history of ISA $(n=92)$ were included in hierarchical logistic regression analyses to examine predictors of prospective ISA (i.e., ISA revictimization). For all analyses, variables were selected for entry into the equation based on Wald forward estimation in three steps: (a) AUDIT scores for alcohol-related problems and marijuana use, (b) negative affect (fear and guilt), and (c) emotion dysregulation (total score, impulsivity subscale)

The first analysis (Model 1) was conducted to determine whether emotion dysregulation (assessed by DERS total score) predicted risk for revictimization after controlling for alcohol problems, marijuana use, and negative affect (see Table 3). Each block was significant; in the third block, marijuana use and DERS total predicted revictimization (guilt was not significant). The nonsignificant Hosmer-Lemeshow test for Block 3 indicated good model fit, $\chi^{2}(8)=8.42, p=.39,-2 \log$ likelihood $=68.42$, Nagelkerke $\mathrm{R}^{2}=.30$. The predictors accurately classified $73.2 \%$ of revictimized women and $70.6 \%$ of nonrevictimized women, with an overall classification rate of $72.7 \%$. In the second analysis, which included only one aspect of emotion dysregulation, impulsivity, each block was significant. In the third block, revictimization was predicted by marijuana use, guilt, and impulsivity. The nonsignificant Hosmer-Lemeshow test for Block 3 indicated good model fit, $\chi^{2}(8)=8.25, p=.41,-2 \log$ likelihood $=69.93$, Nagelkerke $\mathrm{R}^{2}=.35$. The predictors accurately classified $78.9 \%$ of revictimized women and $76.1 \%$ of nonrevictimized women, with an overall classification rate of $76.7 \%$.

\section{Discussion}

Despite earlier evidence linking ISA victimization with heavy episodic drinking (McCauley et al., 2010), in the current study alcohol consumption did not distinguish women at risk for ISA revictimization when considered with other factors. Revictimized women were more likely than expected to exceed the threshold for heavy consumption indicative of alcohol dependence (Dawson et al., 2005), and revictimized women did report more alcohol-related problems and dependence symptoms than did previously victimized women. However, neither of these alcohol-related variables predicted revictimization risk when considered with marijuana use, negative affect, and emotion dysregulation. ISA victimized women (both those who were and were not revictimized) reported very high levels of heavy episodic drinking, with AUDIT-C scores in the clinical range. Thus, the ubiquitous nature of heavy drinking among women with a history of ISA may have prevented consumption variables from emerging as significant predictors of revictimization. Such findings are consistent with a recent study indicating that reductions in women's drinking did not decrease subsequent revictimization risk (Clinton-Sherrod et al., 2011). The present findings, in conjunction with earlier studies, suggest that

Table 2

Differences Between Groups on Emotion Dysregulation and Negative Affect

\begin{tabular}{lcccccc}
\hline & Sample & $\begin{array}{c}\text { Revictimized } \\
(n=17)\end{array}$ & $\begin{array}{c}\text { Previously victimized } \\
(n=71)\end{array}$ & $\begin{array}{c}\text { Nonvictimized } \\
(n=129)\end{array}$ & $F$ & $\eta^{2}$ \\
Cohen's $d$
\end{tabular}

Note. Higher scores indicate greater emotion dysregulation (e.g., greater lack of strategies, awareness, etc.). Groups with different superscripts differ significantly at $p<.05$. Cohen's $d$ was computed only to examine effect sizes for differences between the revictimized and previously victimized groups. Effect sizes for revictimized $>$ nonvictims are not reported. DERS $=$ Difficulties in Emotion Regulation Scale.

${ }^{\dagger} p=.07 .{ }^{*} p<.05$. ${ }^{* *} p<.01 .{ }^{* * * *} p<.001$. 
Table 3

Emotion Dysregulation Predicting the Probability of Incapacitated Sexual Assault Revictimization

\begin{tabular}{|c|c|c|c|c|c|c|c|}
\hline & $B$ & $S E$ & Wald $\chi^{2}$ & $\begin{array}{l}-2 \log \\
\text { likelihood }\end{array}$ & $\begin{array}{c}\text { Nagelkerke } \\
R^{2}\end{array}$ & Odds ratio & $\begin{array}{l}\text { 95\% Confidence } \\
\text { intervals }\end{array}$ \\
\hline \multicolumn{8}{|l|}{ Model $1(n=88)$} \\
\hline Block 1 & & & $6.90^{\text {*:** }}$ & 79.48 & .12 & & \\
\hline Marijuana use & 1.78 & .66 & $7.18^{* * *}$ & & & 5.91 & $1.61,21.67$ \\
\hline Constant & -1.76 & .33 & $29.69^{* * * *}$ & & & & \\
\hline Block 2 & & & $13.34^{* * * * *}$ & 73.05 & .23 & & \\
\hline Marijuana use & 1.73 & .70 & $6.10^{*}$ & & & 5.62 & $1.43,22.10$ \\
\hline Guilt & .16 & .06 & $6.24^{*}$ & & & 1.17 & $1.03,1.32$ \\
\hline Constant & -3.55 & .84 & $17.95^{* * * *}$ & & & & \\
\hline Block 3 & & & $17.96^{* * * *}$ & 68.42 & .30 & & \\
\hline Marijuana use & 1.90 & .75 & $6.51^{*}$ & & & 6.69 & $1.55,28.79$ \\
\hline Guilt & .10 & .07 & $2.08^{\mathrm{ns}}$ & & & 1.11 & $0.97,1.27$ \\
\hline DERS Total & .04 & .02 & $4.31^{*}$ & & & 1.04 & $1.00,1.08$ \\
\hline Constant & -6.27 & 1.71 & 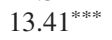 & & & & \\
\hline \multicolumn{8}{|l|}{ Model $2(n=90)$} \\
\hline Block 1 & & & $8.19^{* * *}$ & 84.58 & .14 & & \\
\hline Marijuana USE & 1.84 & .64 & $8.33^{* * *}$ & & & 6.32 & $1.81,22.11$ \\
\hline Constant & -1.69 & .31 & $28.91^{* * * *}$ & & & & \\
\hline Block 2 & & & $15.66^{* * * *}$ & 77.12 & .25 & & \\
\hline Marijuana use & 1.83 & .68 & $7.34^{* * *}$ & & & 6.25 & $1.66,23.51$ \\
\hline Guilt & .16 & .06 & $7.05^{\text {*** }}$ & & & 1.18 & $1.04,1.33$ \\
\hline Constant & -5.62 & 1.33 & $17.98^{* * * * *}$ & & & & \\
\hline Block 3 & & & $22.85^{\text {***** }}$ & 69.93 & .35 & & \\
\hline Marijuana use & 1.68 & .72 & $5.39^{*}$ & & & 5.37 & $1.30,22.17$ \\
\hline Guilt & .15 & .07 & $4.85^{*}$ & & & 1.16 & $1.02,1.32$ \\
\hline Impulse & .21 & .09 & $5.92^{*}$ & & & 1.23 & $1.04,1.45$ \\
\hline Constant & -5.86 & 1.43 & $16.90^{* * * * *}$ & & & & \\
\hline
\end{tabular}

Note. $\quad$ AUDIT $=$ Alcohol Use Disorder Identification Test; DERS $=$ Difficulties in Emotion Regulation Scale; Impulse = Difficulties inhibiting impulsive behavior when distressed. For Models 1 and 2, AUDIT problem scores were nonsignificant predictors in Block 1.

${ }^{*} p<.05 . \quad{ }^{* *} p<.01 .{ }^{* * * *} p<.001$.

heavy drinking or problematic consumption may be a risk factor for ISA in general, rather than ISA revictimization. In contrast to alcohol use, marijuana use was a significant risk factor for ISA revictimization. Drug use, including marijuana use, has been associated with revictimization in earlier investigations (Casey \& Nurius, 2005; Messman-Moore, Ward, \& Brown, 2009). It is unknown how marijuana use may increase risk, as women's drug use is not often associated with sexual assault in event-based studies (Ullman, Karabatsos, \& Koss, 1999). Perhaps marijuana use is a marker of deviant behavior or a deviant peer group, which may increase the likelihood of encountering sexually aggressive men. Additional studies with longer follow-up periods are needed to examine alcohol use and to determine how marijuana and other drugs may contribute to ISA revictimization.

Emotion dysregulation predicted the likelihood of incapacitated sexual revictimization after accounting for the impact of alcoholrelated problems, marijuana use, and negative affect. Impaired emotion regulation likely interferes with a woman's ability to appraise or cope with dangerous situations, thereby impeding appropriate self-protective or escape responses when at imminent risk for revictimization (Dietrich, 2007). Although a global construct of emotion dysregulation predicted ISA revictimization, difficulties inhibiting impulsive behavior when distressed appear to be especially problematic. Individuals who have difficulty controlling impulsive behavior may be at greater risk for ISA revictimization because they do not pause to identify risk or because they lack the capacity to effectively negotiate risky situations. Impulsive women may be more likely to enter high-risk situations or may be more likely to engage in risky drinking practices (e.g., drinking quickly, consuming shots/drinks with high alcoholic content) that increase the likelihood of incapacitation. Findings suggest that even very small increases in emotion dysregulation, particularly impulsivity, increase revictimization risk substantially.

Guilt also predicted ISA revictimization during the study, but only when examined with impulsivity rather than emotion dysregulation broadly defined. Guilt and self-blame are almost universal reactions to sexual assault, and guilt tends to be even more pronounced among revictimized women (Breitenbecher, 2001). Among survivors of interpersonal violence, guilt is associated with increased levels of distress, and predicts avoidant, maladaptive coping-which often includes heavy drinking or drug use (Street, Gibson, \& Holohan, 2005). Although guilt is not associated with weekly or daily drinking (Hussong, Hicks, Levy, \& Curran, 2001), problem drinkers tend to experience heightened levels of negative self-awareness including guilt (Hull, 1981). Women may be particularly vulnerable to revictimization if they are heavy drinkers and experience high levels of guilt.

This is the first prospective study to examine emotion dysregulation as a predictor of ISA revictimization, yet its findings must be considered in the context of some limitations. Given the small sample, predictors of incapacitated and forcible revictimization could not be examined, as only two individuals reported forcible assault in the absence of incapacitation. Although earlier research suggests that alcohol and drug use by victims is typically predictive of incapacitated rather than forcible assault (e.g., Testa, 2004), 
more research in this area is needed to clarify whether emotion dysregulation is as relevant to forcible sexual assault. Findings may also be impacted by the relatively short follow-up period ( 9 weeks). Future studies should aim to balance frequency of participation and potential participant fatigue (i.e., number of questions assessing victimization) with longer follow-up periods. Even in the current brief 10-week study, some participants did not complete all questions, rendering victimization status inconclusive for a significant number of women, and it is not clear how the exclusion of these individuals may have affected the findings reported here. Other factors, such as peak BAC and other aspects of risky drinking should also be assessed to increase our understanding of ISA revictimization. Factors associated with emotion dysregulation and substance use also should be examined, such as PTSD. Given that less than $4 \%$ of college women meet criteria for sexual assault-related PTSD (Read, Ouimette, White, Colder, \& Farrow, 2011), and that college women likely have lower levels of emotion dysregulation when compared to nonclinical samples, such questions may best be answered with more diverse community and clinical samples, increasing generalization of findings reported here. Yet college women are appropriate for study given the high rates of heavy alcohol consumption and ISA in this population (Krebs et al., 2009; Lawyer et al., 2010).

The present prospective study is a significant first step in establishing the relevance of emotion dysregulation as a precursor of incapacitated sexual revictimization. The good news is that emotion regulation skills can be taught, and emotion dysregulation can improve with tools and practice. Interventions designed to promote women's safety and reduce revictimization risk should aim to enhance emotion regulation skills that may reduce risk among the most vulnerable women.

\section{References}

Babor, T. F., Higgins-Biddle, J. C., Saunders, J. B., \& Monteiro, M. G. (2001). AUDIT, the Alcohol Use Disorders Identification Test: Guidelines for use in primary care (2nd ed.). Geneva, Switzerland: World Health Organization.

Bagozzi, R. P. (1993). An examination of the psychometric properties of measures of negative affect in the PANAS-X scales. Journal of Personality and Social Psychology, 65, 836-851. doi:10.1037/0022-3514.65.4 .836

Bernstein, D. P., \& Fink, L. (1998). Childhood Trauma Questionnaire Manual. San Antonio, TX: The Psychological Corporation.

Bradley, B., DeFife, J. A., Guarnaccia, C., Phifer, J., Fani, N., Ressler, K. J., \& Westen, D. (2011). Emotion dysregulation and negative affect: Association with psychiatric symptoms. Journal of Clinical Psychiatry, 72, 685-691. doi:10.4088/JCP.10m06409blu

Breitenbecher, K. H. (2001). Sexual revictimization among women: A review of the literature focusing on empirical investigations. Aggression and Violent Behavior, 6, 415-432. doi:10.1016/S1359-1789(00)00014-8

Casey, E. A., \& Nurius, P. S. (2005). Trauma exposure and sexual revictimization risk: Comparisons across single, multiple incident, and multiple perpetrator victimizations. Violence Against Women, 11, 505-530. doi:10.1177/1077801204274339

Clinton-Sherrod, M., Morgan-Lopez, A. A., Brown, J. M., McMillen, B. A., \& Cowell, A. (2011). Incapacitated sexual violence involving alcohol among college women: The impact of a brief drinking intervention. Violence Against Women, 17, 135-154. doi:10.1177/ 1077801210394272

Dawson, D. A., Grant, B. F., Stinson, F. S., \& Zhou, Y. (2005). Effectiveness of the Derived Alcohol Use Disorders Identification Test
(AUDIT-C) in screening for alcohol use disorders and risk drinking in the US general population. Alcoholism: Clinical and Experimental Research, 29, 844-854. doi:10.1097/01.ALC.0000164374.32229.A2

Dietrich, A. (2007). Child maltreatment and revictimization: The role of affect dysregulation, interpersonal relatedness difficulties and Posttraumatic Stress Disorder. Journal of Trauma \& Dissociation, 8, 25-51. doi:10.1300/J229v08n04_03

Filipas, H. H., \& Ullman, S. E. (2006). Child sexual abuse, coping responses, self-blame, posttraumatic stress disorder, and adult sexual revictimization. Journal of Interpersonal Violence, 21, 652-672. doi: $10.1177 / 0886260506286879$

Fromme, K., Katz, E. C., \& Rivet, K. (1997). Outcome expectancies and risk-taking behavior. Cognitive Therapy and Research, 21, 421-442. doi:10.1023/A:1021932326716

Gratz, K. L., \& Roemer, L. (2004). Multidimensional assessment of emotion regulation and dysregulation: Development, factor structure, and initial validation of the Difficulties in Emotion Regulation Scale. Journal of Psychopathology and Behavioral Assessment, 26, 41-54. doi: 10.1023/B:JOBA.0000007455.08539.94

Gratz, K. L., \& Tull, M. T. (2010). Emotion regulation as a mechanism of change in acceptance-and mindfulness-based treatments. In R. A. Baer (Ed.), Assessing mindfulness and acceptance: Illuminating the processes of change (pp. 107-133). Oakland, CA: New Harbinger.

Hull, J. G. (1981). A self-awareness model of the causes and effects of alcohol consumption. Journal of Abnormal Psychology, 90, 586-600. doi:10.1037/0021-843X.90.6.586

Hussong, A. M., Hicks, R. E., Levy, S. A., \& Curran, P. J. (2001). Specifying the relations between affect and heavy alcohol use among young adults. Journal of Abnormal Psychology, 110, 449-461. doi: 10.1037/0021-843X.110.3.449

Katz, E. C., Fromme, K., \& D’Amico, E. J. (2000). Effects of outcome expectancies and personality on young adults' illicit drug use, heavy drinking, and risky sexual behavior. Cognitive Therapy and Research, 24, 1-22. doi:10.1023/A:1005460107337

Koss, M. P., Abbey, A., Campbell, R., Cook, S., Norris, J., Testa, M., . . White, J. (2007). Revising the SES: A collaborative process to improve assessment of sexual aggression and victimization. Psychology of Women Quarterly, 31, 347-370. doi:10.1111/j.1471-6402.2007.00385.x

Krebs, C. P., Lindquist, C. H., Warner, T. D., Fisher, B. S., \& Martin, S. L. (2009). College women's experiences with physically forced, alcohol- or other drug-enabled and drug-facilitated sexual assault before and since entering college. Journal of American College Health, 57, 639-649. doi:10.3200/JACH.57.6.639-649

Lawyer, S., Resnick, H., Bakanic, V., Burkett, T., \& Kilpatrick, D. (2010). Forcible, drug-facilitated, and incapacitated rape and sexual assault among undergraduate women. Journal of American College Health, 58, 453-460. doi:10.1080/07448480903540515

Magid, V., \& Colder, C. R. (2007). The UPPS impulsive behavior scale: Factor structure and association with college drinking. Personality and Individual Differences, 43, 1927-1937. doi:10.1016/j.paid.2007.06.013

McCauley, J. L., Calhoun, K. S., \& Gidycz, C. A. (2010). Binge drinking and rape: A prospective examination of college women with a history of previous sexual victimization. Journal of Interpersonal Violence, 25, 1655-1668. doi:10.1177/0886260509354580

Messman-Moore, T. L., Walsh, K., \& DiLillo, D. (2010). Emotion dysregulation and risky sexual behavior in revictimization. Child Abuse \& Neglect, 34, 967-976. doi:10.1016/j.chiabu.2010.06.004

Messman-Moore, T. L., Ward, R. M., \& Brown, A. L. (2009). Substance use and PTSD symptoms impact the likelihood of rape and revictimization in college women. Journal of Interpersonal Violence, 24, 499-521. doi:10.1177/0886260508317199

Miranda, R., Meyerson, L. A., Long, P. J., Marx, B. P., \& Simpson, S. M. (2002). Sexual assault and alcohol use: Exploring the self-medication 
hypothesis. Violence and Victims, 17, 205-217. doi:10.1891/vivi.17.2 .205 .33650

Mohler-Kuo, M., Dowdall, G. W., Koss, M. P., \& Wechsler, H. (2004). Correlates of rape while intoxicated in a national sample of college women. Journal of Studies on Alcohol, 65, 37-45.

Read, J. P., Ouimette, P., White, J., Colder, C., \& Farrow, S. (2011). Rates of DSM-IV-TR trauma exposure and posttraumatic stress disorder among newly matriculated college students. Psychological Trauma: Theory, Research, Practice, and Policy, 3, 148-156. doi:10.1037/ a0021260

Street, A. E., Gibson, L. E., \& Holohan, D. R. (2005). Impact of childhood traumatic events, trauma-related guilt, and avoidant coping strategies on PTSD symptoms in female survivors of domestic violence. Journal of Traumatic Stress, 18, 245-252. doi:10.1002/jts.20026

Testa, M. (2004). The role of substance use in male-to-female physical and sexual violence: A brief review and recommendations for future research. Journal of Interpersonal Violence, 19, 1494-1505. doi:10.1177/ 0886260504269701

Testa, M., \& Livingston, J. A. (2009). Alcohol consumption and women's vulnerability to sexual victimization: Can reducing women's drinking prevent rape? Substance Use \& Misuse, 44, 1349-1376. doi:10.1080/ 10826080902961468
Testa, M., Livingston, J. A., VanZile-Tamsen, C., \& Frone. M. R. (2003). The role of women's substance use in vulnerability to forcible and incapacitated rape. Journal of Studies on Alcohol, 64, 756-764.

Ullman, S. E., Karabatsos, G., \& Koss, M. P. (1999). Alcohol and sexual assault in a national sample of college women. Journal of Interpersonal Violence, 14, 603-625. doi:10.1177/088626099014006003

Walsh, K., DiLillo, D., \& Scalora, M. J. (2011). The cumulative impact of sexual revictimization on emotion regulation difficulties: An examination of female inmates. Violence Against Women, 17, 1103-1118. doi: $10.1177 / 1077801211414165$

Watson, D., \& Walker, L. M. (1996). The long-term stability and predictive validity of trait measures of affect. Journal of Personality and Social Psychology, 70, 567-577. doi:10.1037/0022-3514.70.3.567

Wechsler, H., \& Nelson, T. F. (2008). What we have learned from the Harvard School of Public Health College Alcohol Study: Focusing attention on college student alcohol consumption and the environmental conditions that promote it. Journal of Studies on Alcohol and Drugs, 69, 481-490.

Received September 23, 2011

Revision received August 17, 2012

Accepted October 16, 2012 